\title{
Design, Fabrication, and Performance Analysis of an Automatic Horizontal Egg Incubator
}

\author{
Bharosh Kumar Yadav a , Nischal Pokhrel ${ }^{b}$, Dinesh Khatiwada ${ }^{c}$, \\ Madan Khanal ${ }^{d}$, Triratna Bajracharya ${ }^{e}$, Rabin Dhakal ${ }^{f}$ \\ a, b, c, d Department of Mechanical Engineering, Purbanchal Campus, Institute of Engineering, Tribhuvan University, Nepal \\ e Department of Mechanical \& Aerospace Engineering, Pulchowk Campus, Institute of Engineering, Tribhuvan University, Nepal \\ f Department of Mechanical Engineering, Texas Tech University, USA \\ Corresponding Author: ${ }^{a}$ bharosheioepc.edu.np
}

Received: 2020-08-26

Revised: 2021-03-21

Accepted: 2021-03-24

\begin{abstract}
:
This research paper presents the design, construction, and performance testing of an automatic electrically powered egg incubator utilizing the horizontal placement of eggs. This experimental research was driven by the specific design and construction of a well-insulated rectangular egg-incubating box of dimension $400 \mathrm{~mm} \times$ $600 \mathrm{~mm} \times 500 \mathrm{~mm}$ and thickness $30 \mathrm{~mm}$, where sample eggs were kept for experimental test analysis under the favorable temperature and humidity inside the box, which was automatically controlled. The device was made to operate under the temperature range of $37^{\circ} \mathrm{C}-38^{\circ} \mathrm{C}$, which was found to be adequate for developing embryos and also maintaining relative humidity at the range of $45-60 \%$ for the first 18 days and $60-90 \%$ for the last three days. Finally, in this machine, the egg tray was adjusted horizontally, and a motor clamped mechanism was used 5 times a day which was controlled automatically by a micro-controller for the motion of eggs up to 18 days of incubation. In conclusion, this egg-incubating machine has an efficiency and hatchability of $72.22 \%$.
\end{abstract}

Keywords: Temperature, Humidity, Ventilation, Egg turning, Egg Incubating Box

\section{Introduction}

An egg-incubator is a machine, which performs like the broody bird employing temperature, humidity, ventilation, and timely turnings of eggs for embryo development into a chick in 21 days [1]. Incubators are named according to the source used in the incubation of the eggs. The Kerosene stove is a type of incubator that depends on heat from kerosene for the whole 21-day period of incubation [2]. And due to the exorbitant price of petroleum products, this means of production of day-old chicks has proved to be a very expensive process comparing others. Gas incubation also isn't a cheap process due to the high cost of liquefied gas. Solar incubators use solar energy for the overall function. It's a one-time investment project so is costly during installation. Although this system requires minimum operating cost as the energy source is the sun, due to the erratic nature of solar power and its non-availability during the night period this system is less practiced. The only popular existing incubator that is cheap during installation and operation is the electrical type incubator. An electrical incubator is a machine that utilizes an electrical energy supply from the mains. Also, electrical power can be easily stored in batteries so can be easily used during power cutoff periods.

An egg incubator is equipment, which makes farmers produce chicks from eggs without the consent of the mother hen. Incubation of fertile egg is done here by maintaining the incubator environment within the range of $37^{\circ} \mathrm{C}$ to $38^{\circ} \mathrm{C}$ and relative humidity higher than $50 \%$. The incubating Dry Bulb (DB) temperature had not been affected on egg weight loss from Day 0 of incubation to external piping. However, a DB temperature of $37.8^{\circ} \mathrm{C}$ produced significantly heavier chicks at hatch, when the chick weight at hatch was expressed as a percentage of initial egg weight. Relative humidity of $51 \%$ resulted in the greatest weight loss during hatching [3]. Studies investigating the effects of temperature on the development and hatchability of 
poultry embryos have concentrated mainly on the effects of incubator temperature and have ignored the other two factors [4]. Elibol et al. concluded that the fertility of eggs didn't differ due to treatment but hatchability decreased in the large egg weight group primarily due to an increased percentage of late dead. Further, the percentage of late dead decreased as egg weight decreased across all 3 -eggs weight classes and significant interactions of egg weight group and position for percentage fertile hatch-ability, percentage second quality chicks, and percentage late dead embryos [5]. R. Meijerhof suggested that the design of incubators should focus primarily on providing a uniform embryo temperature for all eggs within an incubator with a maximum difference in embryo temperature of $0.3^{\circ} \mathrm{C}$ between individual eggs in the incubator as a goal. [6]. Elibol et al. demonstrated that the turning of eggs during the storage may positively affect the hatching results in the case of both eggs from young and old hens, but the effect is greater when the eggs are generally characterized by a low fertility rate and high survival rate of embryos. They experimented with egg fertilization was at the level of $50.3-83.7 \%$ for the flock at the age of 62 weeks, and therefore much lower compared to the apparent fertilization of eggs from hens from group B (70-73 weeks) in their study: 86.2-90.5\%[7]. Sumit et al. concluded that the poor results are most commonly produced with improper control of temperature and humidity. They found improper control in temperature or humidity is either too high or too low for a required length of time and poor results also occur from improper ventilation regulation, egg turning and sanitation of the machines or eggs [8]. I. Robertson found the most important considerations during overall incubation process are to keep the eggs from overheating and to make sure the suffocation of the embryos that there is an adequate oxygen supply. Eggs must be turned at least 4-6 times daily during the incubation period i.e. to 18 days and must not turn eggs by during the hatching period i.e. after 18 days [9]. R. H. Drent suggested that embryos are moving into hatching position and need no turning. The incubator should be kept closed during hatching to maintain proper temperature and humidity[10] and the air vents should be almost fully open during the latter stages of hatching [11]. H. Wilson studied the most poultry physiological requirements of the developing embryo, turning the optimum incubation temperature of $37^{\circ} \mathrm{C}$ to $38^{\circ} \mathrm{C}$, and small deviations from this optimum are a major impact on hatching success and embryo development[12]. The temperature experienced by the developing embryo is dependent on, incubator temperature, the ability of heat to pass between the incubator and the embryo, and metabolic heat production of the embryo itself[13]. G. Agidi et al. focused on the design, construction, and performance evaluation of an automatic turning mechanism of egg incubator and the percentage hatchability of the incubator was $33 \%$. The incubator cannot function for other eggs such as turkey and the design of the incubator should be motor with a lower rating to avoid high turning speed, need a constant supply of electricity to enable unobstructed operation of the incubator[14]. Also, a micro-controller-based 30 chicken egg incubator for small-scale poultry production was designed and developed by Rogelio and Vinyl. The egg fertility and hatchability were found to be $55 \%$ and $27 \%$, respectively[15]. Abraham et al. concluded that incubation of poultry eggs is very important these days as the demand for chicken is increasing day by day. But the process of hatching eggs by the conventional method is very difficult also consumes much power. They found solar poultry incubator the power consumption of the incubator reduced by $75 \%$ and the cost involved in the design also yields profit and hence can bring out a revolution in this field[16].

The literature review assures that the need for chicken (eggs) is important and increasing day by day in human life. This paper presents the design, fabrication, and performance testing of an automatic electrically powered egg incubator utilizing the horizontal placement of eggs. The experimented incubator machine found a hatchability of $72.22 \%$. This research encourages manufacturers, poultry businesses, and demand this egg incubator will be highest in agricultural countries like Nepal.

\section{Methodology}

The micro-controller plays a vital role, which controls virtually all the devices and sensors of the incubator for providing the right conditions at a right time for incubation of poultry eggs [17]. The incubating machine designs physical nature and economic in material usage. The heat was generated by heating rod and filament lamps in the heating chamber, which was controlled by the micro-controller and finely distributed throughout the incubator chamber by the flow of forced convective air using centrifugal fans installed in 
strategic areas inside the machine. The relative humidity of the air, as well as balanced temperature conditions, were maintained inside the incubator chamber by the micro-controller for the whole period of incubation of the poultry eggs.

\subsection{Circuit Model of Egg Incubating Machine}

The model of the egg incubator includes the micro-controller (Arduino Uno) as the micro-controller for controlling the overall incubating system which is shown in Figure 1. The device operated between the temperature range of $37^{\circ} \mathrm{C}$ to $38^{\circ} \mathrm{C}$ and the humidity between $54 \sim 60 \%$. The controlling system includes the DHT22 sensor and RTC DS1307 sensor to measure the temperature and humidity inside the incubating zone. RTC DSC1307 indicates the Real-Time Clock which counts 31 days as a month automatically. It helps to counts second, minutes, hours, date of the month, day of the week, and a year respectively. The operational range and sensitivity of the sensor used in this incubating machine are shown in table 1 .

Table 1: Sensor operational range and sensitivity

\begin{tabular}{|l|l|}
\hline Model & DHT 22 \\
\hline Power Supply & $3.3-6 \mathrm{~V}$ DC \\
\hline Output signal & Digital signal via single-bus \\
\hline Sensing Element & Polymer capacitor \\
\hline Operating Range & $\begin{array}{l}\text { Humidity } 0-100 \% \mathrm{RH} ; \\
\text { Temperature }-4080^{\circ} \mathrm{C}\end{array}$ \\
\hline Accuracy & $\begin{array}{l}\text { Humidity } \pm 2 \% \mathrm{RH} \\
\text { (Max } \pm 5 \% \mathrm{RH}) \\
\text { Temperature } 4< \pm 0.5^{\circ} \mathrm{C}\end{array}$ \\
\hline Resolution or Sensitivity & $\begin{array}{l}\text { Humidity } 0.1 \% \mathrm{RH} ; \\
\text { Temperature } 0.1^{\circ} \mathrm{C}\end{array}$ \\
\hline Repeatability & $\begin{array}{l}\text { Humidity } \pm 1 \% \mathrm{RH} ; \\
\text { Temperature } \pm 0.2^{\circ} \mathrm{C}\end{array}$ \\
\hline Humidity Hysteresis & $\pm 0.3 \% \mathrm{RH}$ \\
\hline Long-term Stability & $\pm 0.5 \% \mathrm{RH} /$ Year \\
\hline Sensing Period & Average $2 \mathrm{~s}$ \\
\hline Interchangeability & Fully interchangeable \\
\hline Dimensions & $\begin{array}{l}\text { Small size } 14 \times 18 \times 5.5 \mathrm{~mm} ; \\
\text { Big size } 22 \times 28 \times 5 \mathrm{~mm}\end{array}$ \\
\hline
\end{tabular}

The micro-controller controls the fan, through the fan driver to maintain the humidity as well as controls the motor used for changing the position of eggs utilizing the motor driver. The rating of temperature and humidity of the incubator machine can be seen in the LCD. To maintain the uniform temperature and humidity inside the incubator a) Perfectly isolated (i.e. The housing must be thick enough, no air in or out)

b) Proper heating agent (Power cut off and flow of air should be maintained)

c) Distribution of humidity (Proper)

d) Sensors (Must be placed at the surface of the eggs)

e) The incubator environment should be controlled to prevent wide variation in incubating conditions.

f) Noise and sock should be prevented as much as possible during the incubation process.

\subsubsection{Electronics Control System Design and Fabrication}

The design of the circuit included a micro-controller, which controlled every component and regulated its function. The control system was designed based on the optimum temperature and relative humidity inside the box. This research consists of an electrically powered incubating system of an AC power source $(240 \mathrm{~V}, 50$ $\mathrm{Hz}$ ) driven for full operation of this experiment. Arduino is used as a micro-controller, which distributes the overall operation to each sensor as well as motor. 240v supply was directly connected to the temperature controller, which senses the temperature inside the box and sends a signal to the controller. Then it is connected to a heat source i.e. bulbs and a humidifier. Also, a 240v ac source was converted to a $5 \mathrm{v}$ and $12 \mathrm{v}$ dc source to supply power to the micro-controller and motor driver. LCD, humidity sensor, centrifugal fan, and swirl mechanism were connected to the micro-controller. Here if the temperature goes to the maximum limit i.e. $38^{\circ} \mathrm{C}$ automatically bulbs shut down and only lights if the temperature goes to a lower limit i.e., $37^{\circ} \mathrm{C}$. The swirl mechanism was controlled by a micro-controller using RTC. RTC operates it at an interval of 4 hours i.e. 6 times a day.

\subsubsection{Incubating Chamber Design and Fabrication}

The design of the incubator divided into three compartments as shown in Fig. 2 which is modeled in Auto-CAD. The upper portion of the incubator consists of all the electronic hardware components such as Potentiometer, Candling Light, LED screen, and Switch. The middle portion of the incubator holds a tray, where eggs are placed as shown in figure 2 . The lower compartments were designed for heat and humidification (Water Tank) of the egg incubator machine. The source of the humidifier is Heating Rod $(25 \mathrm{~W})$, and for Heating it acts as a primary source 


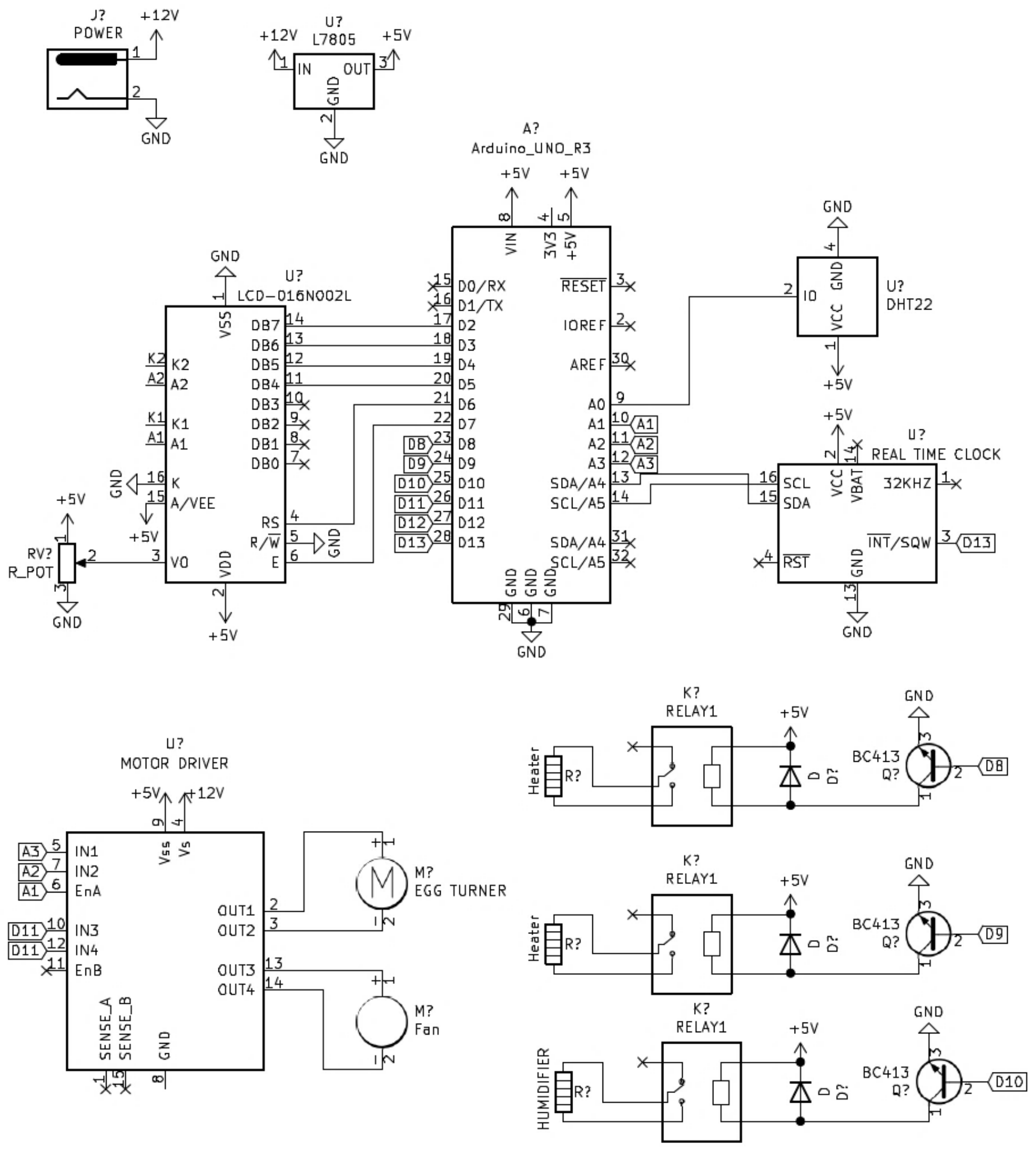

Figure 1: Overall Circuit Diagram of Egg Incubator 


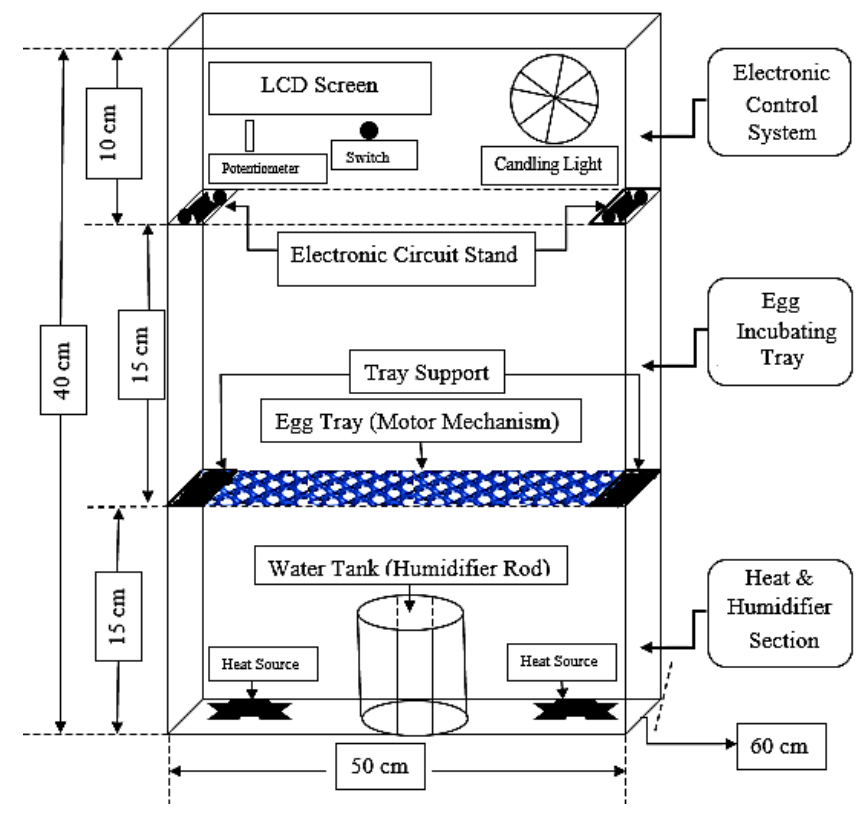

Figure 2: Dimensions of Egg Incubator

while filament lamp (5W) is also used as secondary for the heating source. The incubator consists of various components, aluminum bars used for proper alignments. Polyethene foam which is easily available utilized for making incubator isolated. The tray portion is designed and fabricated in such a way that it experiences horizontal motion for the needful change in position of the eggs automatically with the bearing attached at the base of the egg tray. The experimental research tests which are driven by the specific design and construction of a well-insulated rectangular egg-incubating box of dimension $400 \mathrm{~mm} \times 600 \mathrm{~mm} \times 500 \mathrm{~mm}$ and thickness $30 \mathrm{~mm}$ are fabricated. The fabrication and experimental tests were done successfully using the laboratory of Tribhuvan University, Institute of Engineering, Department of Mechanical Engineering, Purwanchal Campus, Dharan-08, Nepal[18].

\subsection{Initial Trial Test}

Several initial tests and modifications as per requirement performed on the incubating machine before starting the incubation test to avoid different unusual failures on the system.

\subsection{Final (Incubation) Test}

Forty eggs in total having fertility of $90 \%$ were bought from Regional Agricultural Research Center, Tarahara, and were successfully placed on an incubating tray. Initially, every component like heat and humidity sensor, rotation of the motor, heating elements, humidifying, all their working were tested and made as required after loading of eggs. For better monitoring of the incubating condition, a mercury thermometer and a digital electric thermostat were used, and also a buzzer was used to notify the time for rotation of eggs, to check the movement/rotation of eggs. The electric supply was made using an inverter thus problem with the monitoring power supply was maintained but proper monitoring of the incubator is required because of the highly sensitive hatching process. For the better performance of the incubator system, motor mechanism, eggs proper rotation tests from 1 st and 2 nd test data recorded to determine the optimum temperature and humidity conditions. The incubator system was chosen major source (avionics component) $100 \mathrm{w}$ and a minor source $10 \mathrm{w}$, temperature limit $37^{\circ} \mathrm{C}$, and operated economically during the experimental tests. The automatic motor mechanism fabricated incubator turns 5 times a day, given a humidity limit of $55 \%$ for the first 18 days and $80 \%$ after found to be generous growth of embryos.

\section{Observation and Results}

Forty chicken eggs were used for the testing period. Out of these, 4 eggs were cracked during initial testing and thirty-six eggs had completely developed into an embryo which is shown in Figure 3 (a-f) respectively. As a complete result of twenty-six eggs were successfully hatched into chicks after 21 days. The total number of eggs used for hatching is 36 and number of eggs hatched (fertilized eggs) is 26. Thus, the efficiency and fertility of this egg incubator machine is given by:

$$
\begin{aligned}
\text { Efficiency } & =\frac{\text { number of eggs hatched }}{\text { total number of eggs }} \times 100 \% \\
& =\frac{26}{36} \times 100 \%=73 \% \text { (Approx.) }
\end{aligned}
$$

Also,

$$
\begin{aligned}
\text { Fertility of eggs } & =\frac{\text { number of fertile eggs }}{\text { total number of eggs }} \times 100 \% \\
& =\frac{26}{36} \times 100 \%=73 \% \text { (Approx.) }
\end{aligned}
$$

The observations made on this incubation period are listed below: 


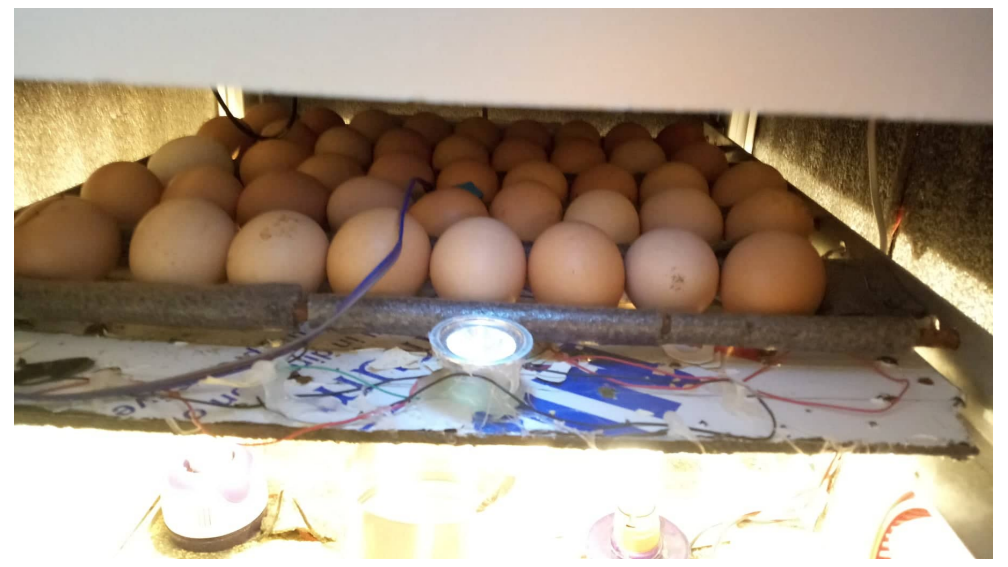

(a)

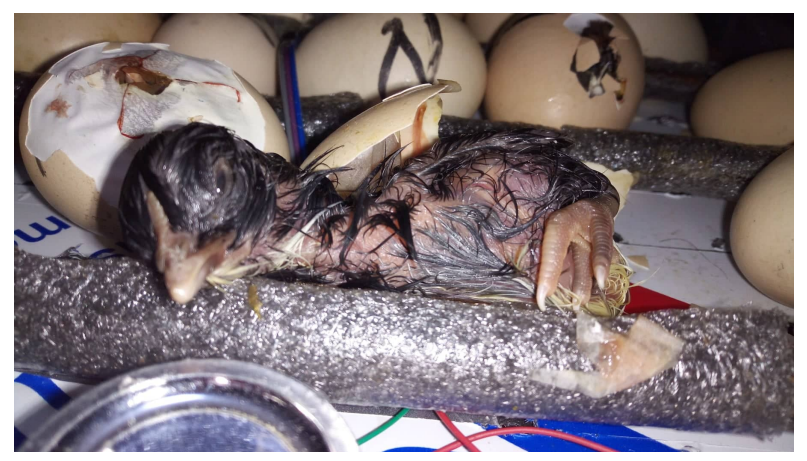

(c)

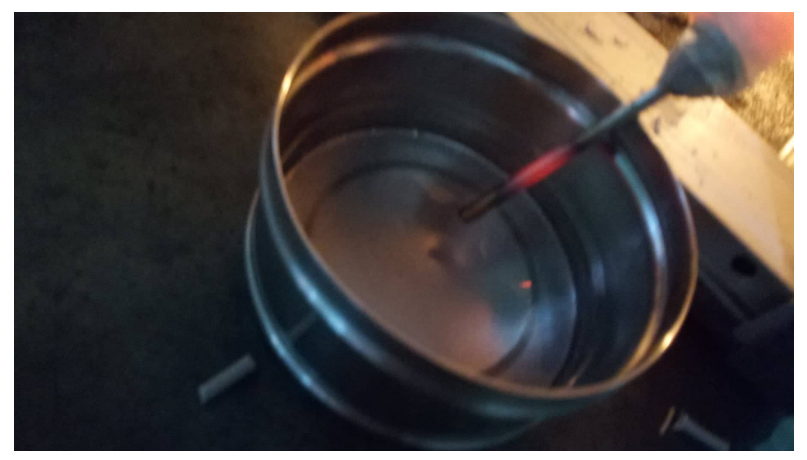

(e)

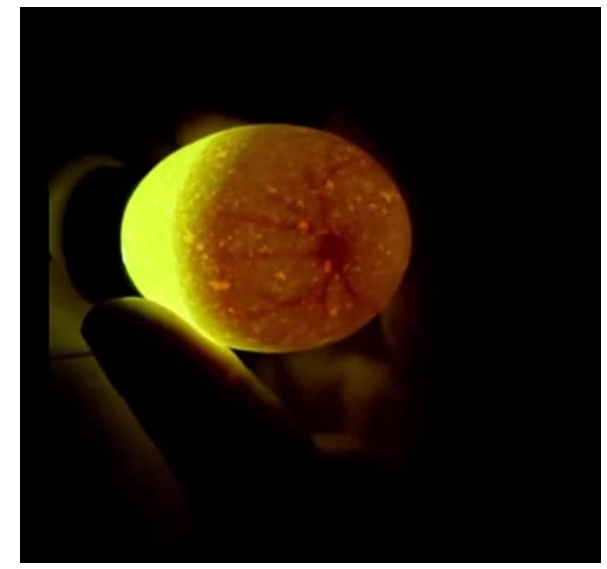

(b)

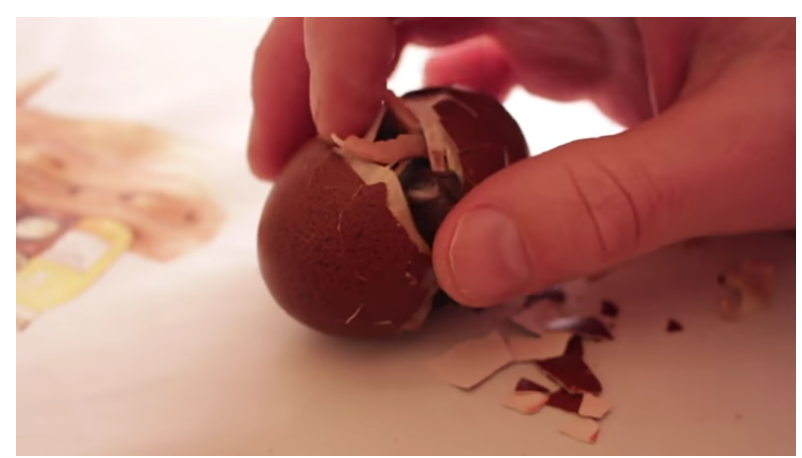

(d)

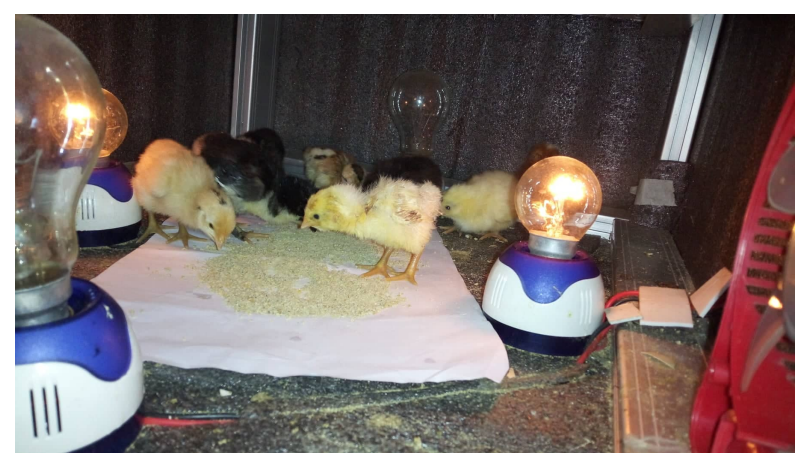

(f)

Figure 3: Images Observed During Incubation Process:

(a) Placing of Eggs into Incubator Tray

(b) Candling of 4th to 5th Day of Incubating Egg

(c) Peeing and Hatching of Chicken from Egg

(d) Helping Chicken to Hatch

(e) Humidifying Rod

(f) Brooding of 1st Day Chicks 


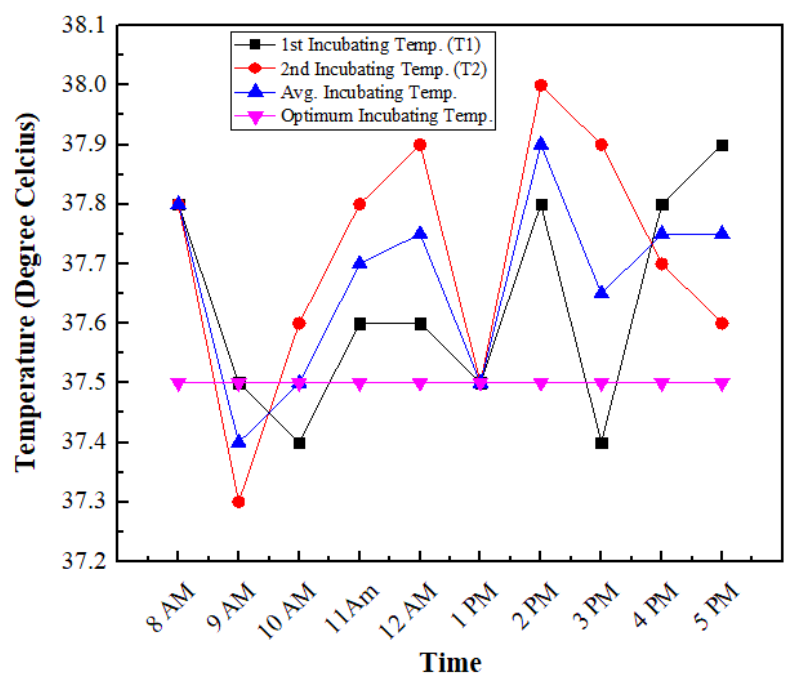

(a)

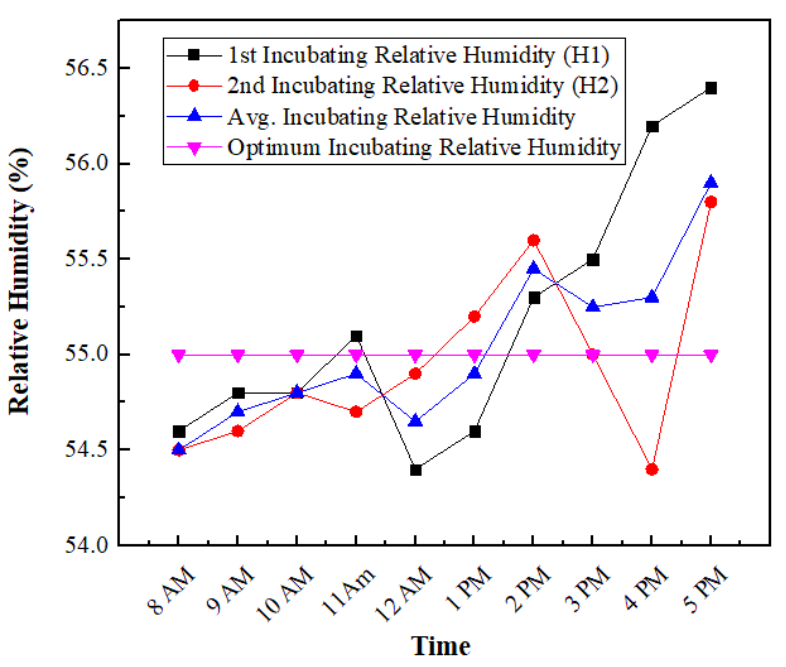

(b)

Figure 4: (a) Temperature Vs Time and (b) Humidity Vs Time (1st Day Incubation)

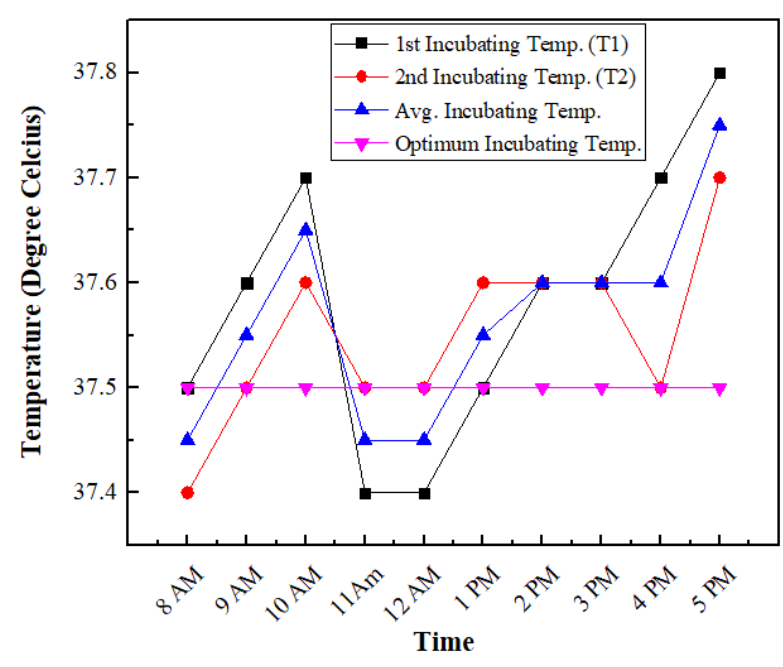

(a)

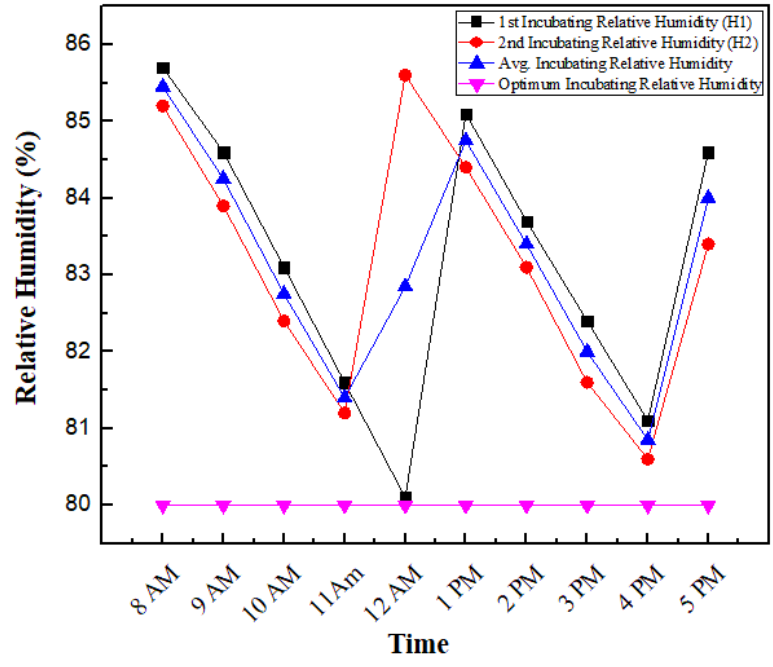

(b)

Figure 5: (a) Temperature Vs Time and (b) Humidity Vs Time (21st Day Incubation) 
i) Temperature and Humidity play a vital role. There must be uniform temperature and Humidity to obtain the well-developed Embryo.

ii) If the temperature exceeds more than $38^{\circ} \mathrm{C}$ and decreases less than $36^{\circ} \mathrm{C}$, it leads to the death of Embryos. So, there must be a uniform temperature.

The constant temperature and humidity inside the incubator are required for the healthy development of the embryo, and $37.5^{\circ} \mathrm{C}$ is found to be the optimum favorable temperature of this fabricated egg incubator machine. The continuous observations was made during the test period of 21 days are depicted in the graphical representation of temperature versus time and humidity versus time, and the data recorded. To increase the efficiency and hatchability of the egg incubator there should be a uniform distribution of the temperature and humidity. The starting of an hour temperature is taken as the first incubating temperature as $\mathrm{T} 1$, and after $30 \mathrm{~min}$ of $\mathrm{T} 1$, the second incubating temperature is taken as $\mathrm{T} 2$. The optimum temperature constant of $37.5^{\circ} \mathrm{C}$ and optimum humidity for the first 18 days were $55 \%$ and the rest 3 days were $80 \%$ which is shown in Figure 4 and Figure 5 of the 1st day and 21 st day of the incubating process respectively.

The result of the experimental research shows that this egg-incubating machine has a hatchability of $72.22 \%$. This research is fully based on the role of temperature, humidity, and the results seen during this incubation period (1st Day to 21st Day) are shown in above Figure 4 and Figure 5 respectively. In summary, the relative humidity maintained within the incubator throughout the egg incubation process was between $54-56 \%$ for 18 days and $80-86 \%$ for the last three days.

\section{Conclusion and Recommendations}

This experimental research is driven by the specific design and fabrication of a well-insulated rectangular egg-incubating box of dimensions $400 \mathrm{~mm} \times 600 \mathrm{~mm} \times$ $500 \mathrm{~mm}$ and thickness $30 \mathrm{~mm}$. The sample eggs were kept in the egg-incubator for experimental test analysis under favorable temperature and humidity. The device was made automatically controlled under the temperature range of $37^{\circ} \mathrm{C}-38^{\circ} \mathrm{C}$, relative humidity at the range of $54-56 \%$ for 18 days and $80-86 \%$ for the last 3 days to operate which were found to be an adequate environment of the system for developing egg embryo. The egg tray adjusted horizontally, motor clamped movement mechanism projected 5 times a day automatically controlled by a micro-controller, and horizontal motion projected to the sample eggs up to 18 days of incubation. The experimental test results concluded that the efficiency and automatic hatchability of these egg-incubating machines is $72.22 \%$.

It is recommended that further improvements can be associated with a change in uniform heating and humidity control electronic systems to increase efficiency and hatchability.

\section{Acknowledgments}

This research was supported by the "Students' Final Year Research Fund" of Tribhuvan University, Institute of Engineering, Purwanchal Campus, Dharan-08, Nepal.

\section{References}

[1] P. J. Clauer, Beginning of life: a leader's manual for avian embryology 1994.

[2] T. Dessie, 'Rice-husk incubation of chicken eggs, 1995.

[3] G. S. SWANN and J. Brake, "Effect of incubation drybulb and wet-bulb temperatures on time of hatch and chick weight at hatch," Poultry Science, vol. 69, no. 6, pp. 887-897, 1990.

[4] N. French, "Modeling incubation temperature: the effects of incubator design, embryonic development, and egg size," Poultry science, vol. 76, no. 1, pp. 124-133, 1997.

[5] O. Elibol and J. Brake, "Effect of egg weight and position relative to incubator fan on broiler hatchability and chick quality," Poultry science, vol. 87, no. 9, pp. 1913-1918, 2008.

[6] R. Meijerhof, "Design and operation of commercial incubators," in Practical aspects of commercial incubation. Ratite Conference Books, Lincolnshire UK, 2002.

[7] O. Elibol and J. Brake, "Effect of egg position during three and fourteen days of storage and turning frequency during subsequent incubation on hatchability of broiler hatching eggs," Poultry Science, vol. 87, no. 6, pp. 1237 $1241,2008$.

[8] T. W. Smith. "Care and Incubation of Hatching Eggs," Successful Hatching Guide For Poultry Operators Agriculture. http://www. nairaland.com (Accessed on March 21, 2020). 
[9] I. Robertson, "The influence of turning on the hatchability of hens' eggs I. The effect of rate of turning on hatchability," The Journal of Agricultural Science, vol. 57, no. 1, pp. 49-56, 1961.

[10] R. H. Drent, "Functional aspects of incubation in the Herring Gull,” Behaviour. Supplement, pp. 1-132, 1970.

[11] U. O. Illinois. "From Egg to Chick: Incubation Procedures,"

http: / / chickscope.beckman. uiuc.edu (Accessed on March 21, 2020).

[12] H. Wilson, "Physiological requirements of the developing embryo: temperature and turning," Avian incubation, pp. 145-156, 1990.

[13] T. Shafey, H. Al-Batshan, M. Shalaby, and M. Ghannam, "Incubation temperature and hemoglobin dielectric of chicken embryos incubated under the influence of electric field," Electromagnetic biology and medicine, vol. 25, no. 2, pp. 87-96, 2006.

[14] G. Agidi, J. Liberty, O. Gunre, and G. Owa, "Design, construction and performance evaluation of an electric powered egg incubator," IJRET: International Journal of Research in Engineering and Technology, vol. 3, no. 03, pp. 521-526, 2014.

[15] B. Paguntalan and V. H. Oquino, "Design and Development of a Microcontroller based Egg Incubator for Small Scale Poultry Production," Global Journal of Science Frontier Research, vol. 16, no. 2, pp. 43-48, 2016.

[16] N. T. Abraham, S. L. Mathew, and C. Kumar, "Design and Implementation of Solar PV poultry incubator," International Journal of Engineering and Advanced Technology, vol. 3, no. 3, pp. 289-291, 2014.

[17] G. Corkery, S. Ward, C. Kenny, and P. Hemmingway, "Incorporating smart sensing technologies into the poultry industry," Journal of World's Poultry Research, vol. 3, no. 4, pp. 106-128, 2013.

[18] B. K. Yadav, P. K. Rauniyar, K. Sudhakar, T. R. Bajracharya, and S. S. Priya, "Sustainable green campus in Nepal: 3E analysis," International Journal of Low-Carbon Technologies, vol. 15, no. 4, 2020. 
